\title{
Surgical treatment options for aldosteronomas
}

\author{
Virgilijus Beišă, Marius Kryžauskas², Gintaras Simutis' ${ }^{1}$, Audrius Šileikis ${ }^{1}, K_{\text {Kęstutis Strupas }}^{1}$ \\ ${ }^{1}$ Centre of Abdominal Surgery, Vilnius University Hospital Santariskiu Clinics, Lithuania \\ 2Faculty of Medicine, Vilnius University, Lithuania
}

Videosurgery Miniinv 2012; 7 (4): 260-267

DOI: $10.5114 /$ wiitm.2011.29898

\begin{abstract}
Introduction: Single access retroperitoneoscopic adrenalectomy (SARA) is the most feasible approach for removing aldosteronomas.

Aim: To analyse the advantages and disadvantages of surgical approaches to treating small adrenal tumours.

Material and methods: In the period 2002-2011, 31 patients were operated on at Vilnius University Hospital Santariskiu Clinics for aldosteronomas. Adrenalectomies were performed in the lateral laparoscopic (group $A, n=6$ ), the endoscopic retroperitoneal (group B, $n=20$ ), and the single incision laparoscopic surgery (SILS) and SARA (group C, $n=5)$ approaches. Seventy five percent of patients were operated on by the same surgeon. The duration of adrenalectomies, and intraoperative and postoperative complications were compared. The possibility of minimally invasive adrenalectomies was evaluated.

Results: According to the patients' age, body mass index and tumour size, the groups were equal. The average duration of surgery in group $A$ was shorter than in groups B and C ( $91 \pm 23 \mathrm{~min}$ vs. $118 \pm 57 \mathrm{~min}$ vs. $144 \pm 88 \mathrm{~min}$ ). Right laparoscopic adrenalectomy was longer than the left ( $105 \pm 26 \mathrm{~min} v \mathrm{vs} .77 \pm 6 \mathrm{~min})$, whereas right endoscopic retroperitoneal adrenalectomy was shorter than the left (109 $\pm 50 \mathrm{~min} v \mathrm{vs} .126 \pm 57 \mathrm{~min})$. The best cosmetic view was in group $C$. The SARA method was converted into the endoscopic retroperitoneal approach and then into the laparoscopic for one patient. There were no intraoperative or postoperative complications.

Conclusions: Evaluating the minimal invasion of the method, its abilities and simplicity of conversion into another type of endoscopic surgical way, the SARA approach should be the first option for removing aldosteronomas.
\end{abstract}

Key words: hyperaldosteronism, aldosteronoma, laparoscopic adrenalectomy, endoscopic adrenalectomy, single incision laparoscopic surgery, single access retroperitoneoscopic adrenalectomy.

\section{Introduction}

Hyperaldosteronism (also known as aldosteronism) is the common name of closely related clinical conditions for which chronic increased secretion of aldosterone is characteristic. Hyperaldosteronism is classified into two types: primary (PA) and secondary (SA) hyperaldosteronism; the latter is not related to adrenal pathology [1].

There are two causes of PA: bilateral adrenal cortical nodal hyperplasia, also called bilateral idiopathic hyperaldosteronism (IHA, 60\% cases), and adrenal cortical adenoma - aldosteronoma (Conn's adenoma, $\sim 35 \%$ cases) [1]. Rare causes of PA are primary adrenal hyperplasia ( $2 \%$ of cases), adrenal cortical carcinoma producing aldosterone ( $<1 \%$ of cases), familial hyperaldosteronism ( $<3 \%$ of cases) and adenoma or carcinoma that is located in the ectopic region and producing aldosterone ( $<0.1 \%$ of cases) [2].

In the case of SA, aldosterone is excreted in the adrenals as a response to the activation of the renin-

Address for correspondence:

Virgilijus Beiša MD, Prof. (HP), Centre of Abdominal Surgery, Vilnius University Hospital Santariskiu Clinics, Santariskiu 2, Vilnius LT-08661, Lithuania, phone: +37052365250, e-mail: virgilijus.beisa@santa.lt 
angiotensin system because of decreased renal perfusion (renal arteriole sclerosis and/or renal arterial stenosis); hypovolaemia, oedema (nephrotic syndrome, cirrhosis or congestive heart failure). During pregnancy, the concentration of plasma renin increases because of the intensity of oestrogen production [1].

Aldosteronoma (Conn's adenoma), unilateral nodal hyperplasia and aldosterone-producing carcinoma are treated in the surgical approach. Bilateral adrenal nodal hyperplasia and familial hyperaldosteronism are treated with medicaments $[3,4]$. The only possible way of treating SA is medical treatment [5].

Until 2004, at Vilnius University Hospital Santariskiu Clinics all adrenal tumours with a diameter up to $8 \mathrm{~cm}$ (including aldosteronomas) were removed in the lateral laparoscopic way. Since 2004, all adrenal tumours with a diameter up to $6 \mathrm{~cm}$ have been removed from the back side: in the endoscopic retroperitoneal (by using three trocars), single incision laparoscopic surgery (SILS) and single access retroperitoneoscopic adrenalectomy (SARA) approaches. Aldosteronoma is a small adrenal tumour: its diameter can range between $1 \mathrm{~cm}$ and $2.5 \mathrm{~cm}$ [6]. In order to define the advantages and disadvantages of laparoscopic and various endoscopic retroperitoneal adrenalectomies, we compared three homogeneous groups of patients with small adrenal tumours of the same size (Conn's adenomas).

\section{Aim}

There are two purposes of this article. The first one is to analyse the advantages and disadvantages of surgical approaches to treating small adrenal tumours (aldosteronomas). The second one is to show the simplicity of SARA conversion to an endoscopic retroperitoneal approach without extra financial costs.

\section{Material and methods}

During 2002-2011, 31 patients were operated on at Vilnius University Hospital Santariskiu Clinics for Conn's adenomas. The clinical diagnosis of aldosteronoma was made and the differential diagnostics were accomplished in the Department of Endocrinology for all these patients. Ultrasound and computed tomography or magnetic resonance imaging (CT/MRI) examinations were performed before the surgery in order to establish the sizes of adrenal tumours. After the surgery, removed tissues were assessed by histological examination.
Adrenalectomies were performed in the lateral laparoscopic, endoscopic retroperitoneal, SILS and SARA approaches. The duration of adrenalectomies, and intraoperative and postoperative complications were compared. The advantages and disadvantages of different types of surgery were defined.

\section{Surgical methods}

\section{Lateral laparoscopic adrenalectomy}

The surgery is performed under general anaesthesia. The patient is placed in the lateral decubitus position (the patient is positioned on one side flexed through the torso at a $30^{\circ}$ angle with a roller beneath). The surgeon and assistant stand in front of the patient, the first assistant on the opposite side. A Veress needle is inserted into the abdominal cavity $2 \mathrm{~cm}$ below the costal margin, along midclavicular line. Twelve $\mathrm{mm} \mathrm{Hg}$ pneumoperitoneum is created by insufflation of carbon dioxide. After that, four $10 \mathrm{~mm}$ diameter trocars are introduced $2 \mathrm{~cm}$ below the costal margin, along the midclavicular line, the anterior axillary line, the midaxillary line and the posterior axillary line in the abdominal cavity.

If surgery is being done on the right side, the patient is placed on the left side. A liver retractor is inserted in the first trocar, the second one is used for the scissors or ultrasound scalpel, the third one for the $30^{\circ}$ optics and the fourth trocar is used for forceps (Figure 1).

The right triangular ligament is cut and the peritoneum is incised along the lower margin of the right liver lobe. The right lobe of the liver is retracted superomedially. A Kocher manoeuvre is performed to release the duodenum. The inferior vena cava and the

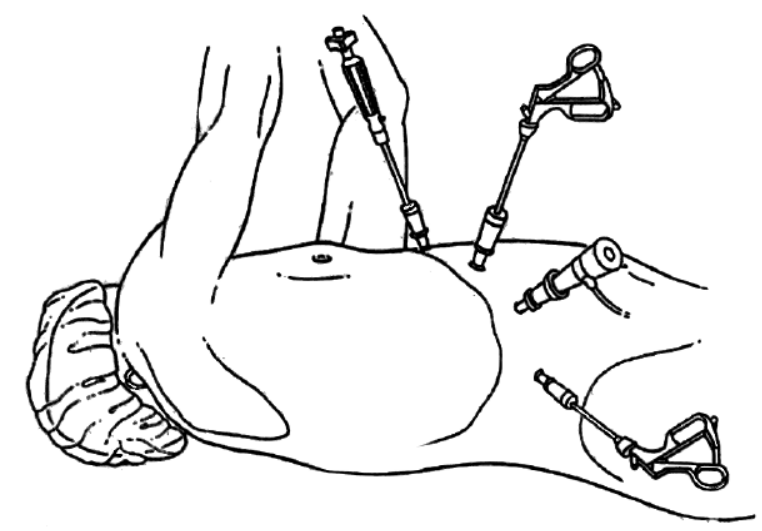

Figure 1. Right lateral laparoscopic adrenalectomy. Positions of patient and trocars 
upper pole of the right kidney are mobilized. The right adrenal is prepared between inferior vena cava and the upper pole of the kidney. The separation is started from the medial margin. Small vessels are coagulated or transected with the ultrasound scalpel. Central vein before conjunction with inferior vena cava is clamped with 2 metal clips and transected. The upper and the lower adrenal poles are mobilized. The separated adrenal is placed in a retrieval bag and extracted through the expanded opening of insertion of the second trocar.

If surgery is being done on the left side, the patient is placed on the right side. A spleen retractor is inserted in the first trocar, the second one is used for forceps, the third one for the $30^{\circ}$ optics and the fourth trocar is used for the ultrasound scalpel or scissors.

Phrenicocolic ligament is cut and the left colic flexure is mobilized. After that, the large intestine is retracted downwards. The peritoneum and phrenicocolic ligament are cut from the lower to the upper spleen pole laterally. The tail of the pancreas is also mobilized along with the spleen. Then, the spleen is retracted medially. Under the tail of the pancreas, the left adrenal is separated more medially from the upper pole of the left kidney. At the inferomedial margin, central vein is clamped with two metal clips before conjunction with left renal vein. The vein is transected between the clips. The superomedial margin of the left adrenal is mobilized. Small vessels are coagulated or transected with the ultrasound scalpel. The lateral adrenal margin is mobilized. The separated adrenal is placed in a retrieval bag and extracted through the expanded opening of insertion of the third trocar.

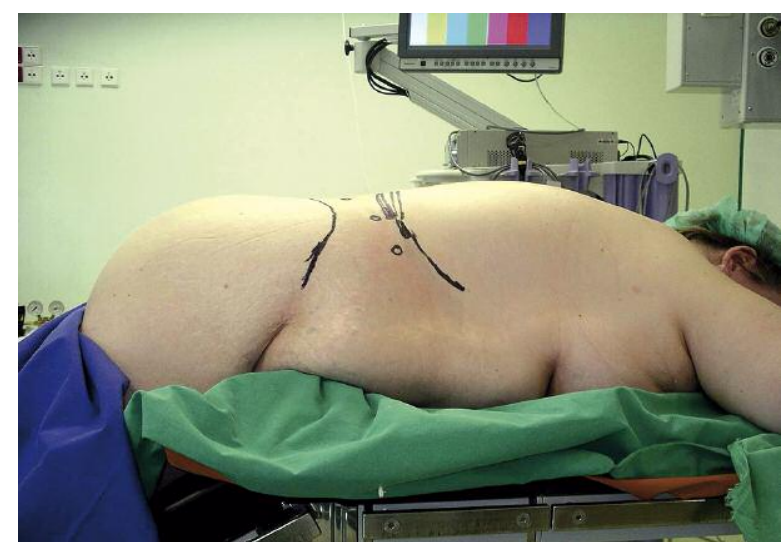

Figure 2. Retroperitoneal endoscopic adrenalectomy. Placement of trocars
The latter opening is sutured with a double stitch: the muscles and the aponeurosis of the external oblique muscle are sutured with two individual absorbable 3/0 stitches and the skin is sutured with 1 or 2 individual stitches. The drain is not inserted. The openings of the other trocar insertions are sutured only with individual skin stitches.

\section{Retroperitoneal endoscopic adrenalectomy}

The surgery is performed under general anaesthesia. The patient is placed in the prone jack-knife position (the patient lies face-down, with raised and flexed arms beside the head and flexed through the torso at a $30^{\circ}$ angle) (Figure 2) or the above-mentioned lateral decubitus position (flexed through the torso at a $45^{\circ}$ angle). The surgeon and assistant stand on the side of the operating adrenal.

A $1.5 \mathrm{~cm}$ transverse incision is made at the tip of rib XII. After preparing the subcutaneous and muscular layers, thoracolumbar fascia is dissected. Following these steps, the retroperitoneal space is accessed and a small cavity is prepared digitally (Figure 3 ).

A $10 \mathrm{~mm}$ trocar for the ultrasound scalpel is placed under finger guidance at the tip of rib XI. In the same way, a $10 \mathrm{~mm}$ trocar for forceps is introduced 4-5 $\mathrm{cm}$ medially and $2 \mathrm{~cm}$ beneath the tip of rib XII. A $10 \mathrm{~mm}$ trocar for the $30^{\circ}$ optics is placed through the first incision at the tip of rib XII, and the skin incision is pressurized with 1-2 skin stitches. The capnoretroperitoneum is created by insufflating $\mathrm{CO}_{2}$ until the pressure gradient reaches $20 \mathrm{~mm} \mathrm{Hg}$.

The upper renal pole and the adrenal are uncovered during the preparation of tissues in the retroperitoneal space and the adipose capsule of kidney

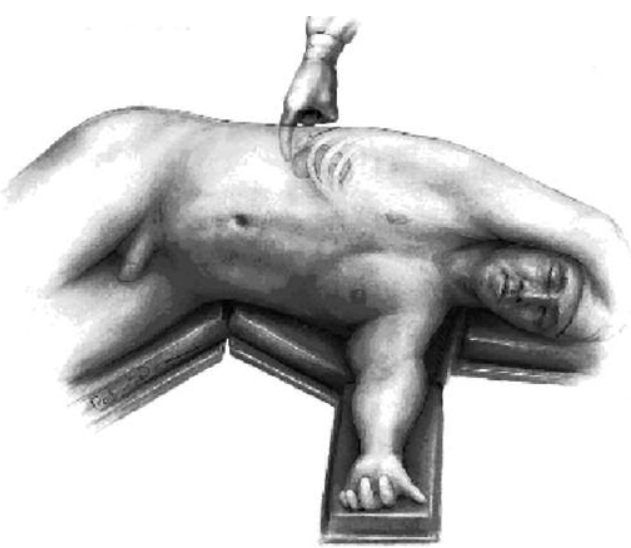

Figure 3. Creation of a cavity using finger in the retroperitoneal space 
with the ultrasound scalpel and forceps. Central vein which conjoins with interior vena cava is also mobilized on the right side. Operating on the left side, the upper renal pole is mobilized and the kidney is pulled down. The left adrenal and its central vein which conjoins with left renal vein are also mobilized. Central vein is clamped with two clips and transected. The adrenal is separated from the surrounding tissues and placed in a retrieval bag. The optics are re-inserted through the second or third trocar and the retrieval bag is extracted through the biggest first trocar opening. The drain is not inserted. The incisions are sutured with individual skin stitches.

\section{Single incision laparoscopic surgery adrenalectomy}

This type of surgery is analogical to the abovementioned endoscopic retroperitoneal approach, but it is performed through a single $3 \mathrm{~cm}$ incision at the tip of rib XII. The muscles of the torso are perforated with a straight clamp, opened and an instrument with three working channels - TriPort ${ }^{\circledR}$ (Olimpus, Europe Holding GmbH, Hamburg, Germany) or SILS Port ${ }^{\circledR}$ (Covidien, Gosport, UK) - is inserted through the wound opening. Five $\mathrm{mm}$ or $10 \mathrm{~mm} 30^{\circ}$ optics are inserted in one channel and a $5 \mathrm{~mm}$-diameter ultrasound scalpel and forceps are placed in the two others (Figure 4).

Usual instruments of laparoscopic surgery are used. Curved instruments, which were specially designed for this surgical approach, are adapted for surgery in the abdominal cavity. They are not intended for manipulations in a small retroperitoneal space. The process of surgery is analogical to the usual re-

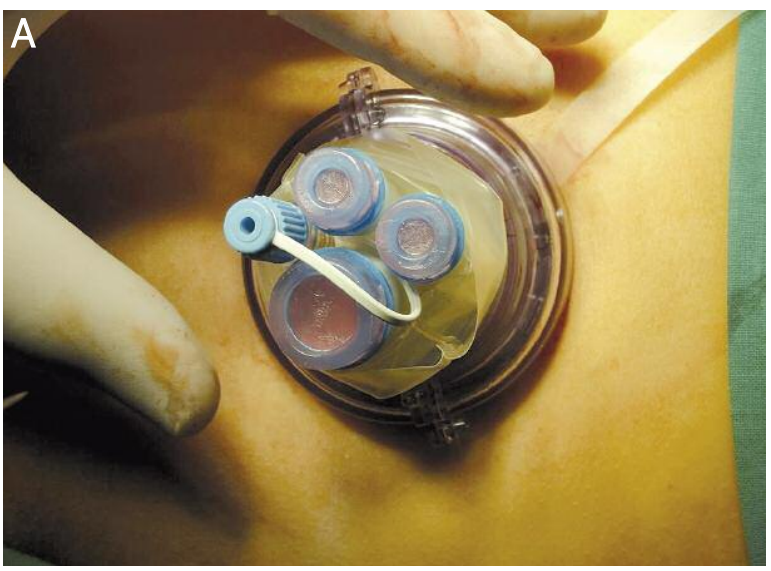

Figure 4. Retroperitoneal adrenalectomy. A - TriPort $^{\circledR}$ (Olympus), B - SILS Port ${ }^{\circledR}$ (Covidien)

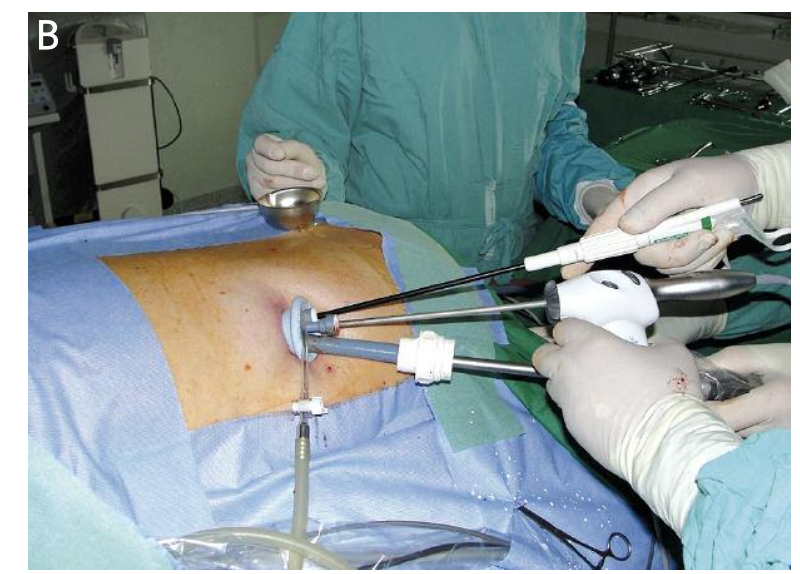

troperitoneal endoscopic adrenalectomy. The mobilized adrenal is placed in a retrieval bag and extracted along with a single port device. The drain is not inserted. The muscles of the torso are sutured with absorbable 3/0 stitches and the skin incision is closed with individual stitches.

\section{Single access retroperitoneoscopic adrenalectomy}

After induction of general anesthesia, the patient is placed in the above-mentioned prone jack-knife position. A $2.5 \mathrm{~cm}$ transverse skin incision is made at the tip of rib XII. The muscles of the torso are perforated and the retroperitoneal space is accessed by using a $10 \mathrm{~mm}$ cutting optical trocar under the endoscopic view with a $10 \mathrm{~mm} 30^{\circ}$ endoscope (Karl Storz Endoskope, Tuttlingen, Germany). The latter endoscope or a $10 \mathrm{~mm}$-diameter metal rod allows a cavity to be created in the retroperitoneal space by performing piston moves. The $10 \mathrm{~mm}$-diameter optical trocar is replaced with a $5 \mathrm{~mm}$-diameter trocar for the same diameter $30^{\circ}$ optics. The second $5 \mathrm{~mm}$ trocar is introduced through the same skin incision for the ultrasound scalpel and for insufflation of carbon dioxide which creates the cavity. Intraperitoneal pressure should reach $20 \mathrm{~mm} \mathrm{Hg}$. The surgeon holds the optics in the left hand and the ultrasound dissector in the right one and prepares the adrenal by manipulating it (Figure 5).

Central vein is coagulated and transected with a bipolar dissector. One of the $5 \mathrm{~mm}$ trocars is replaced with a $10 \mathrm{~mm}$-diameter trocar again after separation of the adrenal from the surrounding tissues. The adrenal is grasped with wide Babcock forceps 


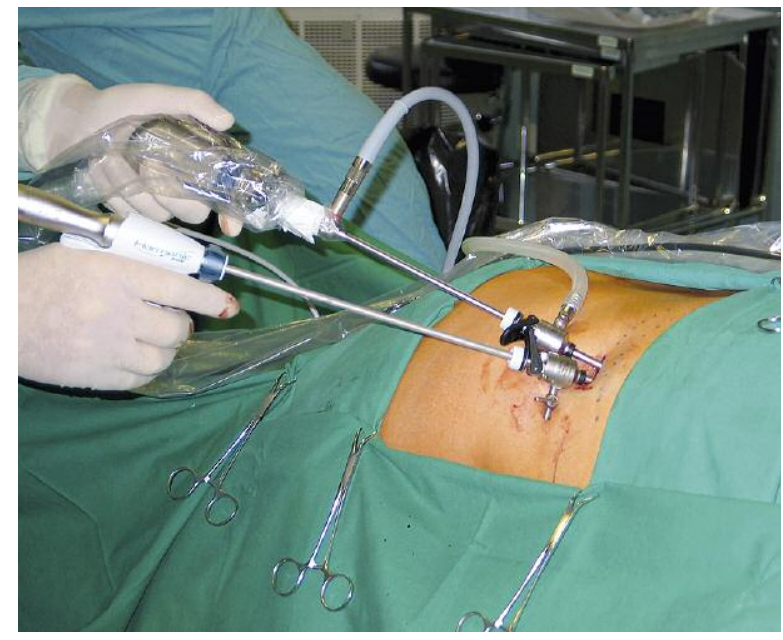

Figure 5. SARA adrenalectomy

and extracted along with the trocar. The drain is not inserted. The skin incision is closed with individual stitches.

\section{Statistical analysis}

Statistical analysis was performed by using the program SPSS 15.0. The $\chi^{2}$ test was applied to compare qualitative variables, and ANOVA for the com- parison of quantitative ones. The mean and the standard deviation were calculated for the quantitative variables. Values of $p$ lower than 0.05 were considered statistically significant.

\section{Results}

The patients treated for aldosteronoma $(n=31)$ were divided into 3 groups according to the method of surgery: group A $(n=6)$ patients had undergone laparoscopic surgery, group B $(n=20)$ the endoscopic retroperitoneal approach, and group $C(n=5)$ the endoscopic retroperitoneal approach through a single incision (1 SILS and 4 SARA adrenalectomies). The means of age, size of aldosteronoma and body mass index (BMI) of the patients of all 3 groups did not differ significantly (Table I).

Computed tomography was performed for 29 of 31 patients and MRI for 2 patients. Before the CT examination, an ultrasound examination was performed for 14 patients: adrenal adenoma was only diagnosed for 9 patients (64\%), no adrenals were seen for 3 patients (21\%), and no morphological changes were found for 2 patients (14\%). The average size of the adrenal tumour for groups A, B and $C$ during CT and MRI was $19 \pm 9 \mathrm{~mm}$ (Figure 6).

Table I. Characteristics of patients

\begin{tabular}{|lllll|}
\hline Variables & Group A $(n=6)$ & Group B $(n=20)$ & Group C $(n=5)$ & Value of $p$ \\
\hline Age [years] & $55 \pm 18$ & $56 \pm 10$ & $58 \pm 11$ & 0.911 \\
\hline Male (M/F) & $1 / 5$ & $7 / 13$ & $1 / 4$ & 0.610 \\
\hline Side (left/right) & $3 / 3$ & $10 / 10$ & $2 / 3$ & 0.919 \\
\hline Tumour diameter [mm] & $20 \pm 4$ & $21 \pm 10$ & $14 \pm 3$ & 0.292 \\
\hline BMI [kg/m²] & $29 \pm 3.7$ & $28 \pm 3.4$ & $30 \pm 2.7$ & 0.429 \\
\hline Characteristics of histological examination & & & 4 & 1 \\
\hline Conn's adenoma & 5 & 16 & - & 0.205 \\
\hline Nodal hyperplasia & 1 & 3 & $144 \pm 88$ & 0.023 \\
\hline Carcinoma & - & 1 & $240 \pm 0$ & 0.604 \\
\hline Average duration of surgery [min] & $91 \pm 23$ & $118 \pm 57$ & $80 \pm 0$ & $13 \pm 7$ \\
\hline Duration of left adrenalectomy [min] & $77 \pm 6$ & $126 \pm 57$ & $109 \pm 50$ & \\
\hline Duration of right adrenalectomy [min] & $105 \pm 26$ & $30 \pm 9$ & & $0.003^{*}$ \\
\hline Blood loss [ml] & $40 \pm 15$ & & & \\
\hline
\end{tabular}

${ }^{*}$ Differences between $A$ vs. $C(p<0.001)$ and B vs. $C(p=0.006)$ 
The average duration of surgery in group $A$ was shorter than in groups B and C (91 \pm 23 min vs. 118 \pm 57 min vs. $144 \pm 88 \mathrm{~min})$. Right laparoscopic adrenalectomy was longer than the left $(105 \pm 26$ min vs. $77 \pm 6 \mathrm{~min}$ ), whereas right endoscopic retroperitoneal adrenalectomy was shorter than the left (109 \pm 50 min vs. $126 \pm 57 \mathrm{~min}$ ). The best cosmetic view was in group $C$ because of the single incision (Table I).

There were no major complications in the intraoperative (bleeding, injuries of other organs) or postoperative (bleeding, haematoma in the abdominal cavity or retroperitoneal space, abscesses, disorders of the cardiovascular system) period in groups A, B and C.

Double conversion was performed for one patient of group C. The SARA method was converted into the endoscopic retroperitoneal approach (by using three trocars), and then into the lateral laparoscopic. The surgery lasted $240 \mathrm{~min}$. The other three SARA operations lasted 80 min each (Table II).

\section{Case report}

Patient 65 years old, BMI $32 \mathrm{~kg} / \mathrm{m}^{2}$, was examined in the Department of Endocrinology for hypertension (arterial blood pressure - 170/100 mm Hg). The plasma concentration of catecholamines was normal; potassium $3 \mathrm{mmol} / \mathrm{l}$; sodium $146 \mathrm{mmol} / \mathrm{l}$; aldosterone in recumbent position $490 \mathrm{ng} / \mathrm{l}$, in the standing position $494.5 \mathrm{ng} / \mathrm{l}$; renin at rest and after load $1 \mathrm{ng} / \mathrm{l}$. According to data from the CT scan, there was a $13 \mathrm{~mm}$ diameter adenoma in the left adrenal. The established diagnosis was aldosteronoma of the left adrenal.

The patient was operated on in the Centre of Abdominal Surgery. The surgery was started using the SARA method by making a $2.5 \mathrm{~cm}$ transverse incision at the tip of rib XII on the left side. However, it was impossible to prepare the adrenal due to abun-

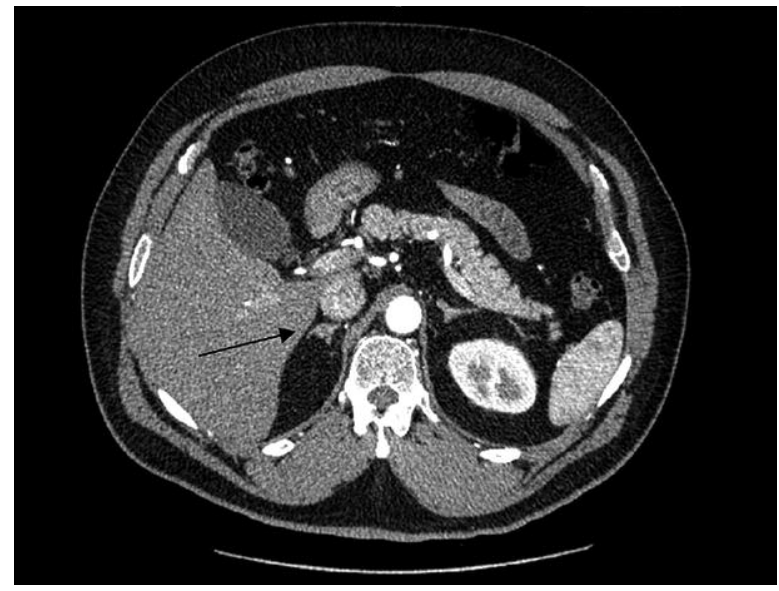

Figure 6. Abdominal CT scan with aldosteronoma of the right adrenal

dant fatty tissue in the renal capsule, the short torso of the patient, aggravated instrument moves and minor anatomical alterations of the left adrenal. Two more $10 \mathrm{~mm}$-diameter trocars were introduced in the retroperitoneal space and the surgery was continued in the endoscopic retroperitoneal approach. Because of the reasons mentioned above and impossibility to find the adrenal within $1 \mathrm{~h}$, the surgery was converted into the lateral laparoscopic approach by turning the patient on the right side. The left adrenal with a $13 \mathrm{~mm}$-diameter aldosteronoma was removed.

There were no intraoperative or postoperative complications; hence the patient was discharged from the hospital two days after the surgery.

\section{Discussion}

In order to compare the advantages and disadvantages of all four methods, we classified patients into three groups with the same pathology and adre-

Table II. Characteristics of patients undergoing SARA and SILS adrenalectomy

\begin{tabular}{|llllllll|}
\hline Patient & Age/sex & $\begin{array}{l}\text { BMI } \\
{\left[\mathrm{kg} / \mathrm{m}^{2}\right]}\end{array}$ & Site & Size $[\mathrm{mm}]$ & Method & $\begin{array}{l}\text { Operative } \\
\text { time }[\mathrm{min}]\end{array}$ & $\begin{array}{l}\text { Blood } \\
\text { loss [ml] }\end{array}$ \\
\hline 1 & $46 / \mathrm{F}$ & 32 & $\mathrm{R}$ & 12 & SARA & 80 & 10 \\
\hline $2^{*}$ & $65 / \mathrm{M}$ & 32 & $\mathrm{~L}$ & 13 & SARA & 240 & 20 \\
\hline 3 & $45 / \mathrm{F}$ & 27 & $\mathrm{R}$ & 12 & SARA & 80 & 20 \\
\hline 4 & $66 / \mathrm{F}$ & 33 & $\mathrm{R}$ & 20 & SARA & 80 & 5 \\
\hline 5 & $67 / \mathrm{F}$ & 28 & $\mathrm{~L}$ & 12 & SILS & 240 & 10 \\
\hline
\end{tabular}

*Double conversion 
nal tumours of similar sizes. Seventy percent of patients of groups $A$ and $B$ and all the patients of group $C$ were operated on by the same surgeon. In the last 15 years, laparoscopic adrenalectomy has become the gold standard in adrenal surgery [7]. In 1992, Gagner announced the first laparoscopic adrenalectomy [8]. The advantages of this method over open surgery have already been proved $[9,10]$. In 1995, Mercan et al. and Walz et al. published an article about the first endoscopic retroperitoneal adrenalectomy [11, 12]. This method soon became popular for its advantages: the adrenals are reached in the shortest way from the back side, the abdominal organs do not need to be mobilized, and due to that no adhesions are formed. Moreover, adhesions in the abdominal cavity after previous laparotomic surgery, hepato- or splenomegaly is not an obstacle to mobilizing the adrenals, bilateral adrenalectomy can be performed without changing the patient's position on the table, and the surgery is performed with three trocars $[13,14]$. If the operation is being performed in the laparoscopic approach, a fourth trocar is necessary for the liver or spleen retractor. Disadvantages of endoscopic retroperitoneal surgery are as follows: there are fewer landmarks in the retroperitoneal space (thus the learning curve of this approach is longer), it is impossible to remove adrenal tumours bigger than $6-7 \mathrm{~cm}$, and there is no possibility to see other abdominal organs or perform simultaneous operations $[13,14]$. According to our data, the duration of laparoscopic surgery is shorter than the endoscopic retroperitoneal approach (91 \pm 23 min vs. $118 \pm 57 \mathrm{~min}$ ). Similar duration of surgery is also reported by other authors [15]. The orientation in the abdominal cavity is easier, but the duration of surgery is not a significant advantage. During endoscopic retroperitoneal surgery, the abdominal organs are not mobilized, so new adhesions in the abdominal cavity are avoided after the surgery $[16,17]$. During the laparoscopic surgery, the liver is an obstacle for mobilizing the right adrenal, and hence the right adrenalectomy lasts longer than the left $(105 \pm 26$ $\min$ vs. $77 \pm 6 \mathrm{~min})$. During endoscopic retroperitoneal adrenalectomy, everything is vice versa: the right adrenalectomy is of shorter duration than the left (109 $\pm 50 \mathrm{~min}$ vs. $126 \pm 57 \mathrm{~min})$. Such differences in time are due to the short central vein of the right adrenal, which enters inferior vena cava at the level of the upper pole of the right kidney. Moreover, the left adrenal is located more medially and dorsally from the left kidney and the central vein enters left renal vein. In order to clamp and transect the central vein, the left kidney should be mobilized and pulled more caudally.

In 2008, Walz and Alesina first performed adrenalectomy in the SARA approach - through a single $1.5 \mathrm{~cm}$ transverse incision from the back side using only two trocars: one for optics and another for bipolar scissors [18]. The adrenal is mobilized with one instrument, so it takes only one surgeon to perform the surgery. The main advantage of this method is the good cosmetic appearance of the surgical wound. However, it is impossible to remove tumours bigger than $3 \mathrm{~cm}$ by applying this method. As a matter of fact, it is perfect for removing Conn's adenomas, the diameter of which mostly does not exceed $2.5 \mathrm{~cm}$. The advantages of endoscopic retroperitoneal adrenalectomy through a single incision using a port (SILS) are: (1) a good cosmetic appearance, (2) a wellsealed retroperitoneal space and (3) the adrenal is mobilized with two instruments [19]. On the other hand, instrumental manipulations in the retroperitoneal space are very limited because of the restricted working space. For this reason, special curved instruments used for SILS in the abdominal cavity are not intended for surgery in the retroperitoneal space [20]. Additionally, the port increases financial costs [21].

Single access retroperitoneoscopic adrenalectomy is performed through a single incision with two trocars. When removing small adrenal tumours in the SARA approach, it is easy to convert it into the endoscopic retroperitoneal method by inserting two more trocars without any extra financial costs. This is the main advantage of SARA over SILS. The diameter of the heads of trocars and the connection between the optical fibre and the optics are very important in the SARA method. It is easier to avoid "crossing" of instruments in the retroperitoneal space. In addition, the optical fibre at the end of the optics causes fewer difficulties in moving instruments while using trocars with small-diameter heads (KARL STORZ GmbH \& Co.).

\section{Conclusions}

Evaluating the minimal invasion of the method, its abilities and simplicity of conversion into another type of endoscopic surgical way, the SARA approach should be the first option for removing aldostero-nomas. 


\section{References}

1. Maitra A. The endocrine system. In: Robbins and Cotran pathologic basis of disease. Kumar V, Abbas AK, Fausto N, et al. (eds.). Saunders Elsevier, Philadelphia 2010.

2. Moraitis A, Stratakis C. Adrenocortical causes of hypertension. Int J Hypertension 2011; Article ID 624691, doi:10.4061/2011/ 624691.

3. Young WF Jr. Endocrine hypertension. In: Williams textbook of endocrinology. Kronenberg HM, Melmed S, Polonsky KS, et al. (eds.). Saunders Elsevier, Philadelphia 2008.

4. Rossi GP, Seccia TM, Pessina AC. Primary aldosteronism. Part II: subtype differentiation and treatment. J Nephrol 2008; 21: 455-62.

5. Thompson NW, Allo MD. The adrenal glands. In: Hardy's textbook of surgery. Hardy JD, Kukora JS, Pass HI. JB. Lippincott Company, Philadelphia 1988.

6. Johnson PT, Horton KM, Fishman EK. Adrenal mass imaging with multidetector CT: pathologic conditions, pearls, and pitfalls. RadioGraphics 2009; 29: 1333-51.

7. Smith CD, Weber CJ, Amerson JR. Laparoscopic adrenalectomy: new gold standard. World J Surg 1999; 23: 389-96.

8. Gagner M, Lacroix A, Bolte E. Laparoscopic adrenalectomy in Cushing's syndrome and pheochromocytoma. N Engl J Med 1992; 327: 1033.

9. Brunt LM, Doherty GM, Norton JA, et al. Laparoscopic adrenalectomy compared to open adrenalectomy for benign adrenal neoplasms. J Am Coll Surg 1996; 183: 1-10.

10. Hallfeldt KKJ, Mussack T, Trupka A, et al. Laparoscopic lateral adrenalectomy versus open posterior adrenalectomy for the treatment of benign adrenal tumors. Surg Endosc 2003; 17: 264-7.

11. Mercan S, Seven R, Ozarmagan S, et al. Endoscopic retroperitoneal adrenalectomy. Surgery 1995; 118: 1071-6.

12. Walz MK, Peitgen K, Krause U, et al. Dorsal retroperitoneoscopic adrenalectomy - a new surgical technique. Zentralbl Chir 1995; 120: $53-8$.

13. Henry JF. Minimally invasive adrenal surgery. Best Pract Res Clin Endocrinol Metab 2001; 15: 149-60.

14. Bonjer HJ, Sorm V, Berends FJ, et al. Endoscopic retroperitoneal adrenalectomy: lessons learned from 111 consecutive cases. Ann Surg 2000; 232: 796-803.

15. Gockel I, Kneist W, Heintz A, et al. Endoscopic adrenalectomy: an analysis of the transperitoneal and retroperitoneal approaches and results of a prospective follow-up study. Surg Endosc 2005; 19: 569-73.

16. Kageyama Y, Kihara K, Kobayashi T, et al. Portless endoscopic adrenalectomy via a single minimal incision using a retroperitoneal approach: experience with initial 30 cases. Int J Urology 2004; 11: 693-9.

17. Major P, Matłok M, Pędziwiatr M, et al. Do we really need routine drainage after laparoscopic adrenalectomy and splenectomy? Videosurgery Miniinv 2012; 7: 33-9.

18. Walz MK, Alesina PF. Single access retroperitoneoscopic adrenalectomy (SARA) - one step beyond in endocrine surgery. Langenbecks Arch Surg 2009; 394: 447-50.
19. Budzyński A, Pędziwiatr M, Matłok M, et al. Preliminary experience with transperitoneal single incision laparoscopic surgery adrenalectomy. Videosurgery Miniinv 2010; 5: 87-92.

20. Beiša V, Simutis G, Lagunavičius K, et al. Single-port endoscopic retroperitoneal adrenalectomy: initial experience. Videosurgery Miniinv 2011; 6: 103-7.

21. Beiša V, Kildušis E, Strupas K. Single access retroperitoneoscopic adrenalectomy: initial experience. Videosurgery Miniinv 2012; 7 : 45-9.

Received: 19.03.2012, Revised: 3.05.2012, Accepted: 29.05.2012. 